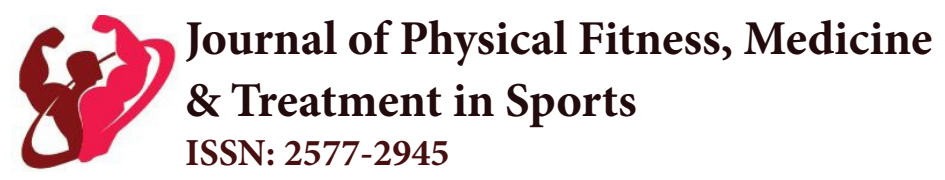

\title{
Clinical Definition and Pathophysiology of Osteoporosis: A Brief Review
}

\author{
Daniel A Jaffe*, Jennifer K Hewit and Todd Crowder \\ Department of Physical Education, United States Military Academy, USA
}

Submission: October 06, 2018; Published: October 17, 2018

*Corresponding author: Daniel A Jaffe, Arvin Cadet Physical Development Center, West Point, New York, USAs, Tel: 845-938-3950,

Email: Daniel.Jaffe@usma.edu

\section{Introduction}

With the field of medical science making constant and dramatic improvements in the treatment and prevention of disease progression, life expectancies in the United States are beginning to increase dramatically, with the elderly population demonstrating the greatest expansion [1]. With this dramatic increase in the elderly population, new and unfounded challenges in managing, treating, and caring for this sector of the population have begun presenting themselves at rates exponential to those of just 20 years ago. In 1990, the American Medical Association stated that "one of the most important tasks that the medical community faces today is to prepare for the problems in caring for the elderly in the 1990's and the $21^{\text {st }}$ century" [2]. The emphasis of this particular study was on the need to develop and sustain means of special care for the growing population of the elderly, who suffered from such diseases as osteoporosis.

Osteoporosis, which is literally defined as "porous bones," is a degenerative disorder responsible for the dramatic decrease in bone density, and loss of bone tissue, over time [3]. The primary cause of this particular ailment is attributed to the excessive losses in bone protein and mineral content, specifically calcium [4]. With the ensuing decrease in bone mass and density, there is a significant decrease in overall skeletal strength, increasing the risk of fractures and breaks due to the increased fragility of bone $[3,5]$. Osteoporosis is diagnosed within individuals presenting a bone mineral density greater than 2.5 standard deviations below the age-predicted norm, as identified using dual X-ray absorptiometry DEXA [6].

By first understanding the basics of bone physiology, researchers have been able to identify physiological factors responsible for osteoporotic progression and development. Bone tissue is constantly in flux, somewhere between resorption and formation, changing shape as a consequence of external, and internal, stressors to which it is exposed [7]. During resorption, osteoclasts digest old bone, while osteoblasts are responsible for deposition and formation of new bone to the matrix. As an individual advance in age from adolescence to early adulthood, a positive balance between formation and removal exists, with greater amounts of bone accumulating than being destroyed. Maximum mass and strength are attained somewhere around 30 years of age, with various extraneous factors influencing the specific time point of maximal density. Once the zenith of bone formation has been attained, a negative balance exists, favoring bone resorption, yielding a progressive decline in bone mineral density and strength with advancing age [7]. Primary osteoporosis is a consequence of the acceleration of this normal aging process, whereas secondary osteoporosis, still caused by an acceleration of bone resorption, can be attributed to outside disease processes or prolonged medication use and/or abuse [3].

Most commonly, osteoporosis will occur in elderly individuals of both sexes, as well as in women following menopause [3]. Additionally, osteoporosis has been found prevalent in younger individuals, both males and females, suffering from disordered eating habits, one of the three key factors in the female athlete triad [8]. The disease directly affects greater than $50 \%$ of males and females greater than 75 years of age, with women being more than five times as likely to develop the disease as a consequence of reduced estrogen, a "bone-protecting" hormone, which is no longer produced in significant quantities, following menopause [4-6]. Greater than 44 million people in North America, both males and females, are at risk for developing osteoporosis [9]. The disease itself is responsible for greater than 1.5 million fractures annually, with the most common point of injury being in the hip, spine, and wrist and Often, many of these fractures will require hospitalization and major surgery to reduce the risk of permanent disability and potential death due to complications [9]. Researchers have estimated that greater than one in five American women, and $13-25 \%$ of males over the age of 50 currently have osteoporosis [10].

The primary known causes of osteoporosis in the older sect of the population are a drop in estrogen in females attributed to menopause, and a decline in testosterone in males attributed to advancing age [3]. Calcium and phosphate, two essential minerals for normal bone formation and function, are reabsorbed by the body at a rate exceeding that of their deposition as an individual 
progress in age. This decline in mineral content yields a dramatic decrease in bone mineral density, resulting in brittle, fragile bones that are far more prone to fractures $[3,6,9]$. In addition to decreased bone mineral density attributed to hormonal declines and fluctuations attributed to age, there exist a litany of other causes of osteoporosis, including but not limited to: confinement to a bed; rheumatoid arthritis; chronic kidney disease; eating disorders; prolonged use of corticosteroid medications, including prednisone; hyperparathyroidism; and Vitamin D deficiency $[3,6,11]$. Additionally, white women, specifically those with a family history of osteoporosis, demonstrate a significantly above average risk of developing osteoporosis [12]. Additional risk factors for developing osteoporosis include: amenorrhea, or an absence of the menstrual cycle; high levels of alcohol consumption; a family history of osteoporosis; prior hormonal treatment of prostate or breast cancer; low body weight; chronic smoking; or, low dietary calcium consumption $[3,6,11]$.

While no symptoms present themselves in the earliest stages of the disease, there are a variety of manifestations of osteoporosis that present themselves during later points in the progression of the disease state. Some of the symptoms include: bone pain and tenderness; fractures with minimal to no trauma or stress exposure; declination in height by as much as 6", attributed to reduced vertebral density concomitant to increased fractures of the spinal bones, as well as progression of kyphosis; as well as low back and neck pain [13]. While Osteoporosis is an incurable progressive disease, there are a variety of treatment paths that can be followed to treat the signs and symptoms of the disease. Ultimately, the goals of osteoporosis treatment include: controlling for, and reducing pain attributed to the disease; slowing down, and potentially stopping, bone loss; reduce and prevent bone fractures with both medication and physical training intervention; and, minimizing the risk of falls that may cause fractures $[14,15]$.

Pharmacological treatments include: biphosphonates, calcitonin, hormone replacement therapy, parathyroid hormone, and Raloxifene. Biphosphanates are the primary medication utilized to both prevent and treat osteoporosis in post-menopausal women [14]. Biphosphatanes can be taken orally e.g. alendronate, ibandronate, and risedronate, or given intravenously. Some of the side-effects include osteonecrossi of the jaw and atypical femur fractures [14]. Calcitonin, administered either intravenously or intra-nasally, is a medication that slows the rate of bone loss and can aid in reducing bone pain [16]. While effective, calcitonin is not as effective as biphosphanates in the treatment of osteoporosis. Hormone replacement therapy which typically entails estrogen and parathyroid hormone (Teriparatide) injections, has declined significantly in application and utilization in recent years [14]. Risk factors associated with hormone replacement therapy include ineffective treatment and sub-optimal recovery when compared to alternative treatments [17]. Finally, Raloxifene, which is similar to the drug tamoxifen, used in the treatment of breast cancer, has been shown to reduce the risk of spinal fractures by almost $50 \%$ [18]. Additionally, raloxifene has been shown to have moderate protective effects against heart disease and breast cancer.
Adversely, raloxifene supplementation demonstrates an increased risk of developing deep venous thrombosis and/or pulmonary emboli [18].

Non-pharmacological interventions include dramatic lifestyle alterations, including diet and exercise modifications, as well as cessation of detrimental behaviors. Regular exercise can dramatically decrease the risk of bone fractures in people suffering from osteoporosis. Exercise interventions demonstrated to have beneficial effects in the treatment of osteoporosis include: weight-bearing exercises like walking, jogging and dancing; resistance exercises including free-weights and resistance bands; and, balance exercises like tai chi and yoga [3]. It is essential to avoid any high risk activities that would increase the risk of falling to prevent potentially debilitating fractures. Regarding nutrient intake, it is essential to ensure a well-balanced diet, rich in phytonutrients and calcium to ensure optimal conditions for healthy skeletal remodeling [10]. Researchers recommend individuals consume a minimum of 1,200 milligrams of calcium and 800-1,000 international units of Vitamin D3 on a daily basis [18,s19]. Some foods identified as high in calcium and Vitamin D include: cheese; ice-cream; green, leafy vegetables; low-fat milk; salmon and sardines; tofu; and, yogurt [19]. Additionally, researchers highly recommend cessation of detrimental habits which significantly contribute to osteoporotic development. Some of these habits include: smoking; alcohol consumption; walking during icy conditions; and, leading a sedentary lifestyle [19].

\section{References}

1. Vermeiren S, Vella Azzopardi R, Beckwee D, Habbiq AK, Scafoglieri A, et al. (2016) Frailty and the prediction of negative health outcomes: A meta-analysis. Journal of the American Medical Directors Association 17(12): 1163.e1-1163.e17.

2. (1990) Council of Scientific Affairs. American Medical Association white paper on elderly health. Report of the Council on Scientific Affairs. Archives of Internal Medicine 150(12): 2459-2472.

3. Cheung CL, Xiao SM, Kung AW (2010) Genetic epidemiology of agerelated osteoporosis and its clinical applications. Nature Reviews Rheumatology 6(9): 507-517.

4. Rabiei M, Masooleh IS, Leyli EK, Nikoukar LR (2013) Salivary calcium concentration as a screening tool for postmenopausal osteoporosis. International Journal of Rheumatic Diseases 16(2): 198-202.

5. Adler RA (2012) Osteoporosis in men: An Update. Rheumatology 31(1): 1-7.

6. Kuroda T, Shiraki M, Shiraki Y, Tanaka S (2012) The importance of absolute bone mineral density in the assessment of antiresorptive agents used for the prevention of osteoporotic fractures. Journal of Clinical Densitometry 19: 1-7.

7. Astrand PO, Rodahl K, Dahl HA, Stromme SB (2003) Textbook of Work Physiology: Physiological Bases of Exercise ( $4^{\text {th }}$ ed). Champaign, IL: Human Kinetics Publishers, Inc.

8. Soleimany G, Dadgostar H, Lotfian S, Moradi Lakeh M, Dadgostar E, et al. (2012) Bone mineral changes and cardiovascular effects among female athletes with chronic menstrual dysfunction. Asian Journal of Sports Medicine 3(1): 53-58.

9. LeMessurier J, O Donnell S, Walsh P, McRae L, Bancej C (2012) The development of national indicators for the surveillance of osteoporosis in Canada. Chronicle of Disability and Injury in Canada 32(2): 101-107. 
10. Adler RA (2012) Osteoporosis in men: An Update. Rheumatology 31(1): 1-7.

11. Aro HT, Alm JJ, Moritz N, Makinen TJ, Lankinen P (2012) Low BMD affects initial stability and delays stem osseointegration in cementless total hip arthroplasty in women. Acta Orthopedia 11: 1-7.

12. Engstrom A, Michaelsson K, Vahter M, Julin B, Wolk A, et al. (2012) Associations between dietary cadmium exposure and bone mineral density and risk of osteoporosis and fractures among women. Bone 24: S171-S177.

13. Cymet Ramirez J, Cisneros Dreinhofer FA, Alvarez Martinez MM, Cruz Gonzalez I, de la FuenteZuno JC, et al. (2011) Diagnosis and treatment of osteoporosis. Position of the Mexican College of Orthopedics and Traumatology. Acta Ortopedica Mexicana 25(5): 303-312.

14. Khosla S, Bilezikian JP, Dempster DW, Lewiecki EM, Miller PD, et al. (2012) Benefits and risk of biphosphate therapy for osteoporosis. Journal of Clinical Endocrinology and Metabolism 20: 1-7.

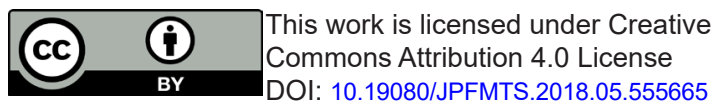

15. Fares A (2018) Pharmacological and non-pharmacological means for prevention of fractures among elderly. International Journal of Preventive Medicine 9: 78.

16. Esenyel M, Icaqasioglu A, Esenyel CZ (2012) Effects of calcitonin on knee osteoarthritis and quality of life. Rheumatology International 28 1-7.

17. Horst Sikorska W, Wawrzyniak A (2011) The role of hormonal therapy in osteoporosis. Endokrynologia Polska 2: 19-22.

18. Murad MH, Drake MT, Mullan RJ, Mauch KF, Stuart LM, et al. (2012) Comparative effectiveness of drug treatments to prevent fragility fractures: A systematic review and network meta-analysis. Journal of Clinical Endocrinology and Metabolism 30: 1-7.

19. Price CT, Langford JR, Liporace FA (2012) Essential nutrients for bone health and a review of their availability in the average North American diet. The Open Orthopaedics Journal 6: 143-149.

\section{Your next submission with Juniper Publishers} will reach you the below assets

- Quality Editorial service

- Swift Peer Review

- Reprints availability

- E-prints Service

- Manuscript Podcast for convenient understanding

- Global attainment for your research

- Manuscript accessibility in different formats (Pdf, E-pub, Full Text, Audio)

- Unceasing customer service

Track the below URL for one-step submission https://juniperpublishers.com/online-submission.php 